\title{
A concepção de Keynes do sistema econômico como um todo orgânico complexo ${ }^{1}$
}

\author{
Fernanda Graziela Cardoso ${ }^{2}$ \\ Gilberto Tadeu Lima ${ }^{3}$
}

\section{Resumo}

O presente artigo argumenta que elementos da abordagem da complexidade, recentemente aplicada à economia, já estavam presentes na obra de Keynes e destaca a fecundidade de uma interação entre elas. A abordagem da complexidade tem como uma idéia central a de que as ações individuais promovem conseqüências não intencionais como resultado de um processo de auto-organização, permitindo o funcionamento do sistema. Keynes explorou tal idéia, por exemplo, na elaboração do paradoxo da poupança, na análise da formação das expectativas e na incorporação do efeito multiplicador. Destaca-se que a complexidade do sistema econômico, segundo a perspectiva de Keynes, começa com a complexidade do ser humano. Por fim, sustenta-se que a visão de Keynes do sistema econômico como um organismo complexo teve a influência do filósofo G. E. Moore.

Palavras-chave: Keynes, John Maynard; Complexidade; Auto-organização.

\section{Abstract \\ Keynes' view of the economic system as a complex organic whole}

This paper claims that some elements of the complexity approach, which has been recently applied to economics, were already contained in Keynes' economics, and argues for the fecundity of an interaction between them. One of the central ideas of the complexity approach is that individual actions have unintended overall consequences as a result of a self-organization process, which allows the functioning of the system. Keynes played around with the idea of unintended consequences of individual actions, for instance, in the formulation of the paradox of parsimony, in the analysis of the expectations formation, and in the inclusion of the multiplier effect. It is argued that the complexity of the economy, from Keynes' perspective, is firstly related to the complexity of the human being. Also, it is suggested that Keynes' view of the economy as a complex organism was influenced by the philosopher G. E. Moore.

Key words: Keynes, John Maynard; Complexity; Self-organization.

JEL B19, B15.

\section{Introdução}

A filosofia de G. E. Moore, tal como enunciada especialmente em seu Principia Ethica (1903), uma das bases da formação intelectual de Keynes, infere

(1) Trabalho recebido em outubro de 2006 e aprovado em dezembro de 2007.

(2) Professora do Instituto de Economia da Universidade Federal do Rio de Janeiro (UFRJ. IE), Rio de Janeiro, RJ, Brasil. E-mail: fgc_13@uol.com.br.

(3) Professor do Departamento de Economia da Faculdade de Economia, Administração e Contabilidade da Universidade de São Paulo (USP. FEA), São Paulo, SP, Brasil. E-mail: giltadeu@usp.br. 
que as conseqüências não devem ser o meio pelo qual se julga o valor de determinada ação, mesmo porque o caráter infinito delas impede que se infira com certeza qual será o seu resultado final. O importante, então, partindo da idéia de que se deve fazer a pergunta certa em vez de tentar chegar a verdades absolutas, é definir qual é o resultado desejado, qual seja, o bom estado da mente.

A abordagem da complexidade, recentemente aplicada à economia, tem como uma idéia central a de que as ações individuais promovem consequiências não intencionais como resultado de um processo de auto-organização, permitindo o funcionamento do sistema. Ou seja, o todo, enquanto propriedade emergente, não é dedutível imediata e diretamente a partir de certo "componente representativo". Em verdade, uma vez que a abordagem da complexidade representa um esforço intelectual ambicioso de compreensão do funcionamento de sistemas altamente organizados, porém descentralizados e compostos de um número muito grande de componentes individuais, heterogêneos, a própria noção de "componente representativo" é insuficientemente representativa.

Por sua vez, o próprio Keynes explora essa idéia de conseqüências não intencionais, o que é patente, por exemplo, na sua elaboração sobre o chamado paradoxo da poupança, na análise da formação das expectativas e na incorporação do efeito multiplicador. Assim, interpretando a abordagem da complexidade a partir da filosofia mooreana, um movimento aparentemente inovador feito por este artigo, no final o que importa não é apontar quais são as consequiências infinitas de determinada ação, mas definir o resultado que se obtém a partir da interação delas. Sobre esse ponto, vale destacar também a definição de probabilidade de Keynes como o grau de crença racional. Pode-se sugerir, então, que tal definição é um desdobramento da visão de Keynes do sistema econômico como um todo orgânico complexo.

Então, a partir da ótica de Keynes, não seria o próprio Moore capaz de conceder um substrato filosófico a essa concepção tipicamente complexa? Em que medida Keynes não herdou de Moore sua concepção de sistema econômico como um organismo complexo? Há uma interessante nota de rodapé em que Keynes cita que Max Planck, o famoso criador da Teoria Quântica, desistiu de estudar economia porque essa lhe parecia muito difícil, o que implicava que a economia é permeada por incertezas. ${ }^{4} \mathrm{E}$ a complexidade da economia decorreria exatamente da complexidade dos átomos que compõem o seu sistema: os seres humanos.

(4) Prossegue Keynes: "Professor Planck could easily master the whole corpus of mathematical economics in a few days. He did not mean that! But the amalgam of logic and intuition and the wide knowledge of facts, most of which are not precise, which is required for economic interpretation in its highest form is, quite truly, overwhelmingly difficult for those whose gift mainly consists in the power to imagine and pursue to their furthest points the implications and prior conditions of comparatively simple facts which are known with a high degree of precision" (CW, X, p. 186n). 
Relembrando a pseudo-analogia entre a queda da maçã e o comportamento humano, num sistema mecânico newtoniano, a queda da maçã depende apenas da força da gravidade, e não da vontade da maçã. Como será argumentado adiante, o que nos parece que Keynes pretende dizer é que o organismo econômico composto de átomos pensantes - é um sistema complexo, no qual, para que a "maçã" realmente caísse, seria necessário "convencê-la". Vale dizer, a "maçã", nesse caso, sendo dotada de vontade e de pensamento estratégico, só cai se ela realmente quiser. ${ }^{5}$

A complexidade da economia, segundo a perspectiva de Keynes, portanto, já está presente na sua concepção de natureza humana: a complexidade do mundo começa com a complexidade do ser humano. O guia prático para os homens lidarem com o futuro, tal como sugerido no famoso artigo de 1937 em resposta a críticos da Teoria Geral (1936) (doravante TG), seria uma instituição racional no sentido de Keynes - para balizar a tomada de decisão em circunstâncias incertas. Aparentemente inovadora, nossa intuição racional - no sentido de Keynes - é que a abordagem da complexidade permite mostrar que Keynes cria racionalmente - no poder da razão como um meio de auto-organização satisfatória do sistema, o que lhe fazia acreditar que o caos não é inevitável. De maneira mais ampla, essa intuição deriva da percepção de que reconhecimento da propriedade de auto-organização como uma tendência persuasiva dos sistemas complexos e adaptativos oferece a possibilidade de descoberta e de análise de regularidades substantivas de sistemas complexos, tal como a economia.

Enfim, o presente artigo pretende, assim como fez Foley (2003) em relação aos economistas políticos clássicos, destacar elementos de uma abordagem tipicamente complexa na obra de Keynes, especialmente a TG. Mas, vale ressaltar que, assim como bem destaca o autor, trata-se, em certa medida, de um exercício de anacronismo, uma vez que a linguagem da abordagem dos sistemas complexos e a sua aplicação a problemas econômicos são relativamente recentes. Não obstante, pode-se dizer que a visão de Keynes do sistema econômico representa uma "antecipação" de uma série de desenvolvimentos posteriores em nível de substância e linguagem dos sistemas complexos.

Para promover tal argumentação, o artigo está estruturado em quatro seções. $\mathrm{Na}$ seção 1 , apresentamos as principais idéias caracterizadoras da

(5) Nas próprias palavras de Keynes: "I also want to emphasize strongly the point about economics being a moral science. I mentioned before that it deals with introspection and with values. I might have added that it deals with motives, expectations, psychological uncertainties. One has to be constantly on guard against treating the material as constant and homogeneous. It is as though the fall of the apple to the ground depended on the apple's motives, on whether it is worthwhile falling on the ground, and the whether the ground wanted the apple to fall. And on mistaken calculations on the part of the apple as how far it was from the center of the earth" (CW, XIV, p. 300).

Economia e Sociedade, Campinas, v. 17, n. 3 (34), p. 359-381, dez. 2008. 
abordagem da complexidade. Na seção 2, argumentamos, a partir do próprio Keynes, que as elaborações filosóficas de Moore embasam a noção de consequiências não intencionais da ação humana e sugerimos que Keynes herdou de Moore a concepção de que o sistema econômico é um organismo complexo, a começar pela natureza humana. A Seção 3 destaca elementos presentes na TG que sugerem a proximidade da visão de Keynes do sistema econômico com a chamada abordagem da complexidade. E, finalmente, na última seção, apresentam-se as considerações e especulações acerca da visão de Keynes do sistema econômico como um todo orgânico complexo.

\section{A abordagem da complexidade}

Na visão de um conjunto expressivo de autores, está se abrindo, pouco a pouco, um novo caminho teórico para a Economia enquanto ciência. Para trilhá-lo, sustenta-se, faz-se necessário abandonar boa parte das maneiras usuais de pensar a realidade econômica, acompanhando-se assim um movimento científico transformador que, atualmente, alcança várias outras ciências, em especial a Física e a Biologia, e que vem sendo caracterizado pela sua orientação voltada à complexidade. $^{6}$

Segundo Foley, em sua detalhada introdução a Albin (1998), uma vez que se contemple seriamente a possibilidade de não-linearidade no comportamento dos agentes, os resultados da complexidade surgem de forma inexorável na teoria social e econômica. E complementa que, se as interações complexas de fato desempenham um papel fundamental na evolução da realidade social, sua abstração pode ter imposto um alto preço para a relevância das teorias social e econômica tradicionalmente aceitas.

Um tomador de decisão racional que se confronta com um sistema dinâmico necessita de uma "máquina" que tenha a capacidade de avaliar as consequiências de suas ações. A maioria dos seres humanos pode lidar com a dinâmica de um sistema com dois ou até três estados distintos, mas, de acordo com Foley, muito poucos podem lidar com mais de dez períodos, sem falar nos milhares ou milhões de estados que facilmente surgem, por exemplo, de transações financeiras complexas. Do ponto de vista epistemológico da teoria neoclássica, o ator econômico racional não precisa considerar as reações detalhadas dos outros atores em toda a sua complexidade potencial, uma vez que o equilíbrio dos preços de mercado representa toda a informação necessária. E, segundo Foley, o aspecto mais falho da teoria do equilíbrio é sua hipótese implícita de que a difusão de informação no mercado não tem custo e é

(6) Para uma introdução mais ampla e aprofundada aos conceitos da abordagem dos sistemas complexos, ver Prigogine e Stengers (1984); Nicolis e Prigogine (1989); Waldrop (1992); Lewin (1992); Holland (1995); Pryor (1995); Horgan (1997); Albin (1998); Rosser (1999) e, mais recentemente, Gribbin (2005). 
instantânea. Para que o programa da escolha racional fosse realmente válido, os agentes precisariam ser capacitados o suficiente para calcular as conseqüências de suas ações. $\mathrm{O}$ autor explicita então que a complexidade do ambiente social reflete o nível de complexidade dos agentes que interagem nele, criando um problema ou um paradoxo insolúvel.

De acordo com Arthur (1999), o que é comum a todos os estudos da complexidade são sistemas com múltiplos elementos que se adaptam ou reagem ao padrão que esses elementos criam. Além disso, os sistemas complexos são sistemas em processo. Nas palavras do autor, "[t]he elements adapt to the worldthe aggregate pattern - they co-create. Time enters naturally here via adjustment and change: as the elements react, the aggregate changes, elements react anew" (p. 1).

Ainda segundo Arthur, os sistemas complexos se tornam interessantes na medida em que contenham não-linearidades ou feedbacks positivos. Tais características, diz o autor, implicam as seguintes propriedades dos sistemas econômicos complexos: uma multiplicidade de "soluções" potenciais; o resultado realmente atingido não é previsível; o sistema tende a ficar "aprisionado" nesse resultado; ele não é necessariamente o mais eficiente economicamente e é dependente do "caminho" adotado - path dependence (p. 2).

Tais sistemas complexos, conforme argumenta Arthur, surgem naturalmente na economia. Os elementos econômicos, ou seja, os agentes humanos, reagem estrategicamente ao considerarem os resultados que podem ocorrer como consequiência da ação que podem realizar. E é exatamente a particularidade desses elementos econômicos que adiciona à economia uma complicação que não existe nas ciências naturais. O autor ainda complementa que, uma vez que se adote a perspectiva da complexidade, com sua ênfase na formação das estruturas, os problemas que envolvem predição na economia parecem ser bem diferentes do que o seriam sob uma perspectiva tradicional. A abordagem da complexidade, conforme o autor, "[p]ortrays the economy not as deterministic, predictable and mechanistic; but as process-dependent, organic and always evolving" (p. 4).

Foley (2003) indica ainda que a abordagem dos sistemas complexos representa um esforço ambicioso em analisar o funcionamento de sistemas altamente organizados, mas descentralizados, compostos de um grande número de componentes individuais. Esses sistemas compartilham um potencial a configurar as suas partes componentes em um grande número de formas - eles são complexos -, apresentam uma constante mudança em resposta a estímulos ambientais e a seu próprio desenvolvimento - são adaptativos -, possuem uma forte tendência a alcançar padrões reconhecíveis e estáveis na sua configuração - são auto- 
organizados - e evitam estados estáveis e auto-reprodutivos - são sistemas que operam fora do equilíbrio.

Ainda segundo Foley, o método da abordagem dos sistemas complexos é altamente empírico e indutivo. Esses modelos freqüentemente envolvem o estudo da interação de um grande número de componentes altamente estilizados e simplificados em simulações computacionais, com o objetivo de identificar propriedades generalizáveis de adaptabilidade e auto-organização comuns a uma grande gama de sistemas complexos. Uma característica desses sistemas complexos estilizados é que seus componentes e regras de interação são, principalmente, não-lineares. Assim sendo, os computadores desempenham um papel crucial nesse tipo de pesquisa, pois se torna impossível inferir diretamente a dinâmica de sistemas não-lineares com um grande número de graus de liberdade usando os métodos analítico-matemáticos clássicos.

Foley aponta que a noção de sistemas complexos impõe maiores mudanças em nossas noções de "senso comum" sobre determinação, previsibilidade e estabilidade. Não se pode esperar modelar o caminho futuro de um sistema complexo em detalhe, por causa da intratável multiplicidade de seus graus de liberdade e dos paradoxos inerentes à sua capacidade de auto-referência e auto-reflexão. O fenômeno da auto-organização, entretanto, abre uma esfera de análise possível. É possível entender as forças que levam à auto-organização de um sistema complexo em algumas dimensões, e modelar esses aspectos limitados do sistema. Ou seja, entender os aspectos auto-organizadores dos sistemas complexos é um conhecimento imensamente valoroso, mas inevitavelmente incompleto.

Foley complementa que a auto-organização de sistemas complexos representa o aparente paradoxo do conhecimento analítico promissor sobre processos evolucionários, sem resultados definidos, os quais são inerentemente imprevisíveis. Aqueles que permanecem comprometidos com a idéia de uma ciência social baseada analiticamente sem adotar a visão de sistemas complexos são forçados a negar o caráter indeterminado e indefinido da vida social humana. Tais pensadores, com a finalidade de tornar a complexidade da vida social passível de análise, tentarão fazer delas formas mais simples. Por outro lado, aqueles que permanecem comprometidos com a visão evolucionária, porém deixam de reconhecer o fenômeno da auto-organização, parecem estar condenados a algum tipo de niilismo epistemológico. O reconhecimento da auto-organização como uma tendência persuasiva dos sistemas complexos e adaptativos oferece a possibilidade de descoberta e de análise de regularidades substantivas de sistemas complexos, tal como a economia, sem precisar estabelecer hipóteses irrealistas de que eles são estados de equilíbrio reconhecidos. 
Assim, sistemas auto-organizados, complexos e adaptativos não podem ser encarados como estando em equilíbrio, tanto no sentido econômico quanto no sentido físico. A auto-organização não pode ocorrer em sistemas dinâmicos estáveis, que tendem a colapsar todas as estruturas dentro de um estado de equilíbrio estável. Estruturas de auto-organização são características de sistemas que, matematicamente, nem são localmente estáveis nem localmente instáveis, que podem sustentar e reproduzir estruturas reconhecíveis através de longos períodos de tempo.

Em suma, de acordo com Arthur, Durlauf e Lane (1997), podem ser identificadas algumas características fundamentais dos sistemas econômicos complexos: são sistemas compostos por agentes idiossincráticos com potencial de aprendizado e adaptação; ocorrem interações entre os componentes do sistema que são coordenadas por normas, instituições e organizações endógenas, não havendo nenhum mecanismo global de controle; tais sistemas apresentam mecanismos de auto-organização e estruturas emergentes que resultam tanto da agregação quanto da interação de suas partes. E, por conta dessas características, o novo emerge recorrentemente no sistema econômico. Logo, o sistema econômico encontra-se em permanente processo de adaptação e opera, em geral, fora do equilíbrio, conforme o sentido clássico do termo.

Por conseguinte, essa orientação voltada à complexidade pretende considerar uma série de características do sistema econômico que não são exploradas e explicadas de modo satisfatório pela teoria econômica dominante. Essa abordagem alternativa busca especificar os agentes e suas regras de comportamento para tentar apreender, por meio de simulações, as propriedades emergentes das interações dos agentes. Tal como na dedução, esse método de simulação inicia-se com a elaboração de um conjunto bem definido de pressupostos, mas diferentemente do método dedutivo, o método de simulação complexo não termina com a prova de um conjunto de teoremas que resumem os resultados obtidos. Assim, a partir de alguns pressupostos e de certas condições iniciais, procura-se gerar de forma sistemática processos evolutivos artificiais interessantes na medida em que eles podem sugerir "propriedades emergentes" não inferíveis dedutivamente.

\section{A influência de Moore sobre Keynes}

$\mathrm{Na}$ presente seção, pretende-se destacar uma das mais importantes influências intelectuais no pensamento de Keynes, qual seja, a do filósofo moral G. E. Moore. Além disso, sugere-se que é inclusive - e, talvez, principalmente dessa influência de Moore que se origina a concepção de Keynes do sistema econômico como um organismo complexo. Vale ressaltar que a análise desenvolvida no compasso desta seção - e mesmo deste artigo - não pressupõe ou 
pretende demonstrar que a influência de Moore tenha sido a única - ou mesmo a mais importante - sofrida por Keynes em matéria filosófica. Afinal, não é nosso propósito - e nem poderia sê-lo no compasso de um artigo - realizar uma análise suficientemente ampla e aprofundada de Keynes enquanto filósofo-economista, o que exigiria analisar adequadamente não somente outras influências filosóficas além de Moore, mas, inclusive, a copiosa literatura que configura o chamado "keynesianismo filosófico", que tem buscado, a partir dos anos 1980, resgatar e analisar textos filosóficos de Keynes e conectá-los com sua teoria econômica. ${ }^{7}$ Dado o propósito mais circunscrito deste artigo, que é o de destacar a proximidade entre a abordagem de Keynes e a abordagem da complexidade recentemente aplicada à economia, a incorporação dessa imensa literatura sobre Keynes enquanto filósofo-economista é, por conseguinte, igualmente circunscrita e seletiva, sendo priorizados autores que fornecem suporte às posições aqui assumidas. Além disso, essa seletividade se justifica pela admissão, desde logo, de que o presente artigo, por necessidade de delimitação e focalização, não pretende destacar e analisar todo o universo de elementos de uma abordagem tipicamente complexa na teoria econômica de Keynes, mas somente alguns deles. ${ }^{8}$ Por exemplo, uma idéia central da abordagem da complexidade é a de que as ações individuais têm consequiências não intencionais, com que o todo, enquanto propriedade emergente, não é dedutível imediata e diretamente de certo

(7) Andrade (2000) mapeia as origens e principais contribuições teóricas do keynesianismo filosófico, destaca seus principais tópicos de pesquisa e avalia suas perspectivas como um corpo de conhecimento alternativo.

(8) Essa seletividade explica, por exemplo, a não-incorporação de elementos da análise realizada em Davis (1994), cujo propósito é rastrear a lógica de desenvolvimento de uma série de idéias filosóficas de Keynes desde suas obras iniciais até a TG. Embora Davis demonstre que, nesse desenvolvimento, é possível perceber que várias dessas idéias sofrem modificações, inclusive algumas oriundas de Moore, isso não conflita com a posição aqui assumida de que a concepção de Keynes do sistema econômico como um organismo complexo teve a influência de Moore. Por exemplo, não parece haver evidência na detalhada análise de Davis de que tenha sido posteriormente revertida a adesão de Keynes à concepção de Moore de que não é possível apontar as conseqüências de determinada ação individual, posto que essas são infinitas. Na verdade, a postulação de Davis (p. 71) de que Keynes, ao contrário da ênfase inicial que deu à intuição e ao julgamento individual, veio a concluir à época da elaboração da TG que era necessário atribuir maior significância à operação de regras e convenções na vida econômica parece fornecer uma corroboração adicional à nossa conjectura de que Keynes intuía a propriedade de auto-organização como uma tendência de um sistema adaptativo complexo como a economia de mercado. A importância - e a natureza social - de regras e convenções, por sua vez, é igualmente destacada por Ludwig Wittgenstein, cujas concepções filosóficas de certa forma influenciaram aquelas de Keynes, como mostrou Davis (1994) - e, de maneira ainda mais ampla e aprofundada, Coates (1996), não incorporado ao presente artigo pela mesma exigência de seletividade, mutatis mutandis, que se aplicou a Davis (1994). É forçoso reconhecer, porém, que Coates (1996), focando o pensamento de Moore, Frank Ramsey, Wittgenstein e Keynes, argumenta persuasivamente que a noção de que o entendimento dos fenômenos complexos da economia e da sociedade demanda que as teorias sejam construídas a partir de conceitos vagos, que carecem de limites rígidos e toleram casos limítrofes, era central à filosofia e economia de Cambridge ao final dos anos 1930. Logo, Coates (1996) seria uma referência essencial em uma investigação orientada pela conjectura de que Wittgenstein, à semelhança de Moore, proporciona substrato filosófico à abordagem da complexidade. 
comportamento individual representativo. Por seu turno, o próprio Keynes explora essa idéia de conseqüências não intencionais, como ilustra o paradoxo da poupança, aparentemente revelando a influência da concepção de Moore de que não é possível apontar as consequiências de determinada ação individual, uma vez que, como veremos a seguir, essas conseqüências são infinitas. Daí nossa conjectura de que Moore proporciona substrato filosófico à concepção de que as ações individuais geram consequiências não intencionais, típica da abordagem da complexidade.

\subsection{O método de Moore e o grupo de Bloomsbury}

Keynes foi para Cambridge exatamente no ano em que o Principia Ethica foi publicado. O grupo de Bloomsbury, do qual Keynes fazia parte, estava numa idade em que as "crenças" - e o otimismo - ainda se fazem presentes. Foram esses sentimentos joviais, estimulados pela filosofia mooreana, que influenciaram a grande maioria deles, o que fez do grupo de Bloomsbury uma comunidade intelectual bastante peculiar. Porém, cada integrante do grupo possuía características extremamente idiossincráticas, sendo que o próprio Keynes se autoclassificava como um não conformista.

Em My Early Beliefs, datado de 1938, Keynes explicita que o que o grupo de Bloomsbury depreendeu de Moore não correspondia ao todo que ele oferecia. Nas palavras do autor, "he had one foot on the threshold of the new heaven, but the other foot in Sidgwick and the Benthamite calculus and the general rules of correct behavior" (1938, p. 436). Assim, de acordo com Keynes, o grupo de Bloomsbury aceitou a "religião" - atitude de alguém em relação a si mesmo - de Moore e descartou a sua moralidade - atitude de alguém em relação ao mundo exterior. De fato, diz Keynes, o que consideravam como uma das maiores vantagens da religião de Moore era que fazia a moral desnecessária. Nas palavras de Keynes (1938),

[n]othing mattered except states of mind, our own and other people's of course, but chiefly our own. These states of mind were not associated with action or achievement or with consequences. They consisted in timeless, passionate states of communion, largely unattached to 'before' and 'after'. Their value depended, in accordance with the principle of organic unity, on the state of affairs as a whole which could not be usefully analysed into parts (p. 436).

Keynes ressalta ainda que foi sob a influência do método de Moore que o grupo de Bloomsbury pôde acreditar que era possível fazer noções essencialmente vagas tornarem-se claras através do uso de linguagem precisa e de perguntas exatas. "O que exatamente você quer dizer?" era a pergunta que norteava as análises e discussões desses intelectuais sob influência direta da filosofia mooreana. 
Moore dizia que a ação prática é tão difícil de avaliar que qualquer tentativa de fazê-lo leva à inação, pois os desdobramentos conseqüentes de uma ação são infinitos. Keynes, por sua vez, acreditava que, muito embora seja difícil avaliar o melhor curso de uma ação, é possível exercer julgamento, ou até seguir um compromisso intuitivo. Para O’Donnell (1989, cap. 6), o jovem Keynes acreditava que uma relativa ignorância em relação ao futuro não é razão suficiente para negar a possibilidade de um julgamento racional sobre as ações. Então, o julgamento racional poderia proceder mesmo em condições de incerteza. Vale aqui enfatizar a noção de animal spirits, uma característica que Keynes atribui aos investidores, ressaltando a sua tendência à ação, e não à inação. Sugerimos, então, que tal abordagem de Keynes seria mais um momento mooreano. ${ }^{9}$

Os intelectuais do grupo de Bloomsbury, diz Keynes, acreditavam num progresso moral contínuo baseado na crença de que a raça humana é composta de pessoas decentes e racionais, influenciadas por padrões verdadeiros e objetivos. Mas, como conseqüência do seu "estado geral de espírito", segundo Keynes, os membros do grupo de Bloomsbury não compreenderam a própria natureza humana, incluindo a deles mesmos. A racionalidade que atribuíram a essa natureza conduziu à superficialidade, não apenas de julgamento, mas também de sentimento. Como apontado por Keynes (1938),

[t] he attribution of rationality to human nature, instead of enriching it, now seems to me to have impoverished it. It ignored certain powerful and valuable springs of feeling. Some of the spontaneous, irrational outbursts of human nature can have a sort value from which our schematism was cut off (p. 448).

Entretanto, apesar de certo repúdio em relação às suas primeiras concepções filosóficas, não exatamente por causa da influência de Moore em si, mas da forma como sua filosofia foi interpretada, é evidente que, mesmo nos trabalhos da fase madura de Keynes, permanece muito do que estabelece a filosofia mooreana, o que será mais bem explicitado na próxima subseção.

\subsection{A presença mooreana na obra de Keynes}

Mini (1991), em uma análise detalhada e cuidadosa do grupo de Bloomsbury, argumenta que Keynes absorveu o realismo e o método de alcançar a verdade de Moore, e os utilizou para formar a base epistemológica da TG. O método de Moore, que consistia em uma análise fria de cada sentença, de cada

(9) Koppl (1991), aparentemente de maneira inovadora e ainda exclusiva, apresenta a origem do conceito animal spirits. Sugere que se trata de um termo originariamente médico e não econômico. Antes de Keynes aplicá-lo à economia, o termo animal spirits havia sido utilizado em teorias remotas de fisiologia para se referir à ação muscular direcionada pelo cérebro. $\mathrm{O}$ autor menciona que parece que Keynes emprestou o termo de Descartes, pois, diz ele, é muito improvável que Keynes desconhecesse o uso de Descartes de tal termo, dado que, além de filósofo e economista, Keynes era um autor erudito. Porém, sugere-se aqui que, em verdade, Keynes o fez em um movimento mooreano, algo não cogitado pelo autor desse artigo. 
palavra, trazendo à tona ambigüidades, fazendo distinções e assim por diante, teve um grande impacto sobre os filósofos de Cambridge e, especialmente, sobre Keynes.

Conceitos e pressuposições que parecem ser enganosamente simples são, na verdade, complexos, a partir de uma perspectiva mooreana, o que implica que um verdadeiro filósofo deve fazer perguntas precisas, fazer distinções se necessário e analisar cada termo exaustivamente. Segundo Mini, "Moore's philosophical priorities are reversed. The method is more important than the conclusion" (1991, p. 71, ênfase original). A partir de tal caracterização, de que o método é mais importante do que a conclusão, diz Mini, é fácil ver como Keynes se apropriou do método de Moore. Enquanto muitos dos predecessores de Keynes permaneceram encantados pela arquitetônica imponente da teoria clássica, Keynes examinou os seus componentes básicos. Longe de ter se impressionado, considerou tal estrutura ilógica, contraditória e superficial, sugerindo que a economia clássica não se tratava de uma análise séria, e sim de uma coleção de relações simples obtidas por intermédio de seu método analógico e retórico. Além disso, acrescentaríamos nós, Keynes não apenas discordava do método e da teoria clássica, mas principalmente da visão clássica, o que configura um movimento tipicamente mooreano. A visão de Keynes do sistema econômico de mercado como um organismo complexo colide com a visão clássica de comportamento agregado bem-comportado como regra, graças a mecanismos virtuosos de ajustamento.

Segundo Mini, Keynes utilizou o método de Moore também para elucidar o significado da incerteza. No seu artigo de 1937, Keynes enfatizou uma distinção ignorada pelos clássicos: a distinção entre a incerteza que é mensurável por probabilidade e cálculo e a incerteza que resulta do fato de não se ter absolutamente nenhuma base para inferir racionalmente o que é mais provável que aconteça, a chamada incerteza fundamental (Dequech, 2000). Ou seja, os economistas clássicos encaravam a incerteza como se fosse apenas da primeira forma, caindo, inevitavelmente, no cálculo benthamita de prazer e dor. Assim, a TG pode ser vista, segundo Mini, como uma afirmação do realismo contra o idealismo que representava a teoria do emprego clássica.

Ainda segundo Mini, o grande objetivo do Principia Ethica de Moore era descobrir os princípios fundamentais da razão ética. De acordo com o autor, Moore não tinha a ilusão de que a ética era uma ciência: não se podem inferir certezas na ética por causa da ignorância que circunda as consequiências de nossas decisões. Como os efeitos de um ato continuam por um tempo indefinido, nosso conhecimento dos efeitos futuros será extremamente falho, então não há como saber quais ações produzem o bem. Se insistirmos em aplicar padrões rígidos para julgar o que é certo ou é errado, estaremos inaptos a decidir sobre qualquer regra 
de conduta. Ou seja, a nosso ver, Moore sugeriria, através de seu método, que o conhecimento acerca de um sistema complexo não pode ser julgado a partir de padrões rígidos. Pode-se, então, traçar aqui um paralelo com a observação de Foley (2003), reportada na seção anterior, de que o conhecimento acerca de um sistema complexo é necessariamente incompleto. Mas, diria Moore, por outro lado, se abandonássemos os padrões mais altos e aplicássemos um padrão prático, cotidiano, a ética poderia fornecer algumas regras. E essas regras são aquelas mais universalmente reconhecidas pelo senso comum (Mini, 1991, p. 78-79).

Mas qual foi, afinal, o efeito dessa fase mooreana em Keynes? Mini sugere que ela modelou a sua visão sobre os estados psicológicos e sobre o poder das emoções humanas; concedeu a ele um novo tratamento com relação ao realismo do homem comum; pelo princípio da unidade orgânica, ela aumentou a sua tendência a ver algo como possivelmente relacionado com todo o resto; ela deu uma base filosófica à idéia de incerteza; e, finalmente, destruiu qualquer convicção na forma pragmático-utilitarista de se julgarem as ações humanas apenas pelos resultados (1991, p. 83). Em suma, adicionaríamos nós, Moore proporcionou a Keynes (e, de maneira mais ampla, à própria abordagem da complexidade) um substrato filosófico à visão do sistema econômico como um organismo de natureza complexa.

\subsection{Por que as hipóteses naturais não servem para lidar com o sistema econômico complexo}

Concedendo agora maior ênfase à questão do todo orgânico, de acordo com Carabelli (1988, cap. 5), o caráter atomístico da lei natural, pressuposto pelo princípio da variedade independente, implicava que os métodos indutivos não eram aplicáveis naqueles casos onde o sistema era um complexo orgânico e a lei natural era concebida como um ser orgânico também. Em tais casos, a predição era impossível e o conhecimento de uma parte do sistema poderia não levar nem para o conhecimento provável e tampouco para suas associações com outras partes. Segunda a autora, o que Keynes, no Tratado da Probabilidade (1921) (doravante TP) requeria a priori não era a certeza da hipótese indutiva associada ao princípio da variedade independente, mas, sim, uma probabilidade finita $a$ priori em favor dela (1988, p. 78-79).

Existe uma relação entre a probabilidade a priori da hipótese indutiva e a experiência. As razões colocadas por Keynes para explicar esse ponto, diz Carabelli, eram que há tanta repetição e uniformidade na nossa experiência que se deposita grande confiança na hipótese indutiva. Keynes estava, então, se referindo ao fato de que, quando a experiência contém uma grande quantidade de repetição e uniformidade, a confiança no indutivismo cresce. Mas tal referência estava longe de significar que a experiência, como tal, pode provar a validade de tal hipótese. $\mathrm{O}$ 
sentido da passagem se torna mais claro se levarmos em conta que Keynes estava, na verdade, se referindo mais ao peso do argumento do que à probabilidade da hipótese indutiva. Uma elevação na quantidade de conhecimento leva a uma elevação no peso da hipótese e, por conseguinte, em nossa confiança nela, mais do que propriamente um aumento em sua probabilidade. De acordo com a autora, a rejeição de Keynes da probabilidade objetiva estava em paralelo com a sua crítica das tentativas contemporâneas de reduzir a probabilidade subjetiva à probabilidade matemática (1988, p. 79-80).

Adiante, Carabelli (1988, p. 106) indica que, ao lidar com o problema das leis naturais, Keynes descreveu a hipótese indutiva como o que os matemáticos chamam de "o princípio da superposição de pequenos efeitos", ou como o caráter atomístico das leis naturais. No TP, em seu capítulo 21, Keynes argumenta que o sistema material universal é constituído de "átomos legítimos" (legal atoms). Cada átomo, por sua vez, pode ser tratado, a partir dessa teoria, como uma causa separada e, portanto, não entra em combinações orgânicas diferentes em que cada uma delas é regulada por leis diferentes. Segundo Keynes, a hipótese atomística poderia vir a ser razoável naquelas situações que apresentassem as características pressupostas pelos matemáticos. Mas, em outros casos, contrapõe Carabelli, para Keynes a aplicação cega do cálculo significaria atribuir a cada relação probabilística as condições limitadas e particulares que devem ser pressupostas para a validade do uso dessa ferramenta, o que equivaleria, então, a transferir para o material sob análise as condições atomistas da aplicação do cálculo. Mas, conforme aponta Carabelli, são casos "such as psychology and moral sciences, in which Keynes thought the 'atomic hypothesis' did not work" (1988, p. 106). Keynes argumentava que a simplicidade é um critério perigoso, sendo que a atitude crítica de Keynes, ainda de acordo com a autora, era proveniente de sua visão organicista. Nas palavras de Keynes: "Mathematical Psychics has not, as a science or study, fulfilled its early promise...[t]he atomic hypothesis which has worked so splendidly in physics break down in psychics. We are faced at every turn with the problems of organic unity, of discreteness, of discontinuity - the whole is not equal to the sum of the parts, comparisons of quantity fail us, small changes produce large effects, the assumptions of a uniform and homogeneous continuum are not satisfied" (CW, X, p. 262, ênfase adicionada). ${ }^{10}$

Ou seja, os atributos do sistema econômico enfatizados nessa passagem, quando avaliados à luz dos conceitos apresentados na seção anterior, podem ser

(10) O termo "psychics" refere-se aqui ao título do livro publicado por F. Y. Edgeworth em 1881, qual seja, Mathematical Physics: An Essay on the Application of Mathematics to the Moral Sciences. No esclarecimento do próprio Keynes, "it can [not] be disputed that for forty years Edgeworth was the most distinguished and most prolific exponent in the world of what he himself dubbed Mathematical Psychics - the niceties and the broadnesses of the application of quasi-mathematical method to the Social Sciences" (1926, p. 256, ênfase original).

Economia e Sociedade, Campinas, v. 17, n. 3 (34), p. 359-381, dez. 2008. 
nitidamente caracterizados como típicos de um sistema complexo, tal como desenvolvido recentemente em várias áreas do conhecimento.

A própria visão de Keynes sobre a probabilidade, de acordo com Carabelli (1988, cap. 8), pode ser vista como organicista. Para Keynes, a probabilidade representaria magnitudes qualitativas, transitórias, organicamente dependentes, únicas e irreversíveis temporalmente, estando seus atributos agrupados sob a noção crucial de complexidade. E era por causa da complexidade das magnitudes envolvidas no cálculo de probabilidade que o conhecimento probabilístico não poderia ser obtido em termos completamente analíticos. A conseqüência dessa postura de Keynes em relação ao cálculo de probabilidade e de sua abordagem peculiar em relação à lógica era a de que, se a concepção atomista da probabilidade envolvia o uso da ferramenta representada pela matemática e pela lógica formal, a adoção de uma abordagem orgânica, por seu turno, envolveria a utilização de uma ferramenta lógica alternativa representada pela linguagem ordinária. Apenas a linguagem ordinária, por contar com uma estrutura aberta, ser compatível com a contradição, ter caráter semântico e revelar capacidade de lidar com agregados não enumeráveis, é que permitiria abordar fenômenos que apresentam atributos de complexidade (1988, p. 148-149).

No TP, Keynes afirma que as leis de causação universal e a uniformidade da natureza, com que todos os eventos teriam alguma causa e a mesma causa sempre produziria o mesmo efeito, ainda que sejam comumente invocados para justificar a validade da indução e da analogia, são princípios que afirmam apenas que há dados a partir dos quais eventos temporalmente posteriores poderiam vir a ser inferidos. Porém, não parecem fornecer muito auxílio para a resolução do problema da indução propriamente dito, ou para a determinação de como é possível inferir uma probabilidade a partir de dados parciais. Segundo Keynes, "[s]tates of the universe, identical in every particular, may never recur, and, even if identical states were to recur, we should not know it" (CW, VIII, p. 276).

Relembrando o exemplo apresentado na introdução do presente artigo, o das "maçãs", sistemas que envolvem elementos dotados de vontade própria - e, portanto, imprevisível -, são inerentemente complexos, tal como definido na primeira seção. Ao agirem, os elementos constituintes do sistema mudam o próprio ambiente em que interagem e, por conta da mudança desse ambiente, os elementos reagem novamente, num processo que não tem fim. Mas, tal caráter infinito de auto-organização desse sistema não necessariamente implica caos ou catástrofe, pois apesar de a economia de mercado não ter mecanismos de autoajustamento virtuosos, o sistema se auto-organiza de uma maneira minimamente estável. Assim, como será argumentado na próxima seção, não importa a caleidoscopia que envolve as relações individuais, pois no agregado sempre 
emerge uma relativa estabilidade. Como intuído - racionalmente, diríamos nós pelo próprio Keynes (1936),

[é] uma das características essenciais do sistema econômico em que vivemos não ser ele violentamente instável, mesmo estando sujeito a severas flutuações no que concerne à produção e ao emprego. Na verdade ele parece apto a permanecer em condições crônicas de atividade subnormal durante um tempo considerável sem tendência marcada para a recuperação ou o colapso completo. Ademais, a evidência prova que o pleno emprego, ou mesmo o aproximadamente pleno, é uma situação tão rara quanto efêmera. As flutuações podem começar de repente, mas parecem atenuar-se antes de chegar a grandes extremos, e o nosso destino é a situação intermediária, não propriamente desesperada e tampouco satisfatória (1936, p. 173, ênfase adicionada).

E, na verdade, pode-se conjecturar que tal estabilidade, enquanto fruto de um processo de auto-organização, como uma propriedade emergente, eventualmente decorre precisamente dessa caleidoscopia. Ou seja, o sistema econômico, enquanto organismo complexo, revela-se evolutivo e adaptativo, sendo caracterizado pela emergência do novo, exatamente em função da heterogeneidade que prevalece em sua estrutura.

\section{O sistema econômico como um organismo complexo na visão de Keynes}

Pretende-se sugerir na presente seção que a teoria do emprego da TG é uma teoria mais adequada a um sistema complexo como o econômico do que a preexistente, na medida em que a visão de Keynes da economia como um sistema complexo the permitiu explicar o seu funcionamento de uma forma não mecanicista. Dessa forma, argumenta-se que o princípio da demanda efetiva é um princípio de determinação adequado à visão de economia complexa. Comparativamente à teoria dita clássica, na TG não são operantes vários automatismos e auto-ajustamentos de mercado, daí a marcada volatilidade, ainda que contida, conforme a citação anterior, do produto e do emprego. ${ }^{11}$ Em suma, a

(11) $\mathrm{Na}$ interpretação da teoria do emprego de Keynes aqui realizada, inspirada na abordagem da complexidade, o princípio da demanda efetiva é o mecanismo essencial de adaptação da produção e do emprego em um economia de mercado. Daí concebermos o ponto de demanda efetiva como propriedade emergente do sistema adaptativo complexo que é a atividade produtiva nessa modalidade de economia. Não surpreende, assim, que um dos principais representantes da abordagem da complexidade, o cientista da computação John Holland, ao descrever os atributos dos sistemas adaptativos complexos, tenha apresentado o multiplicador keynesiano como exemplo de uma propriedade, o efeito multiplicador, de um deles, a existência de fluxos interativos - entre as partes - que variam adaptativamente ao longo do tempo (1995, p. 25). Como bem colocou o economista Peter Howitt, por sua vez, embora sem fazer menção à ilustração anterior de John Holland, "[t]he Keynesian multiplier process is the economist's paradigmatic positive feedback loop, in which an initial departure from fullemployment equilibrium cumulates instead of being corrected" (2006, p. 33). Os interessados em uma derivação formal original de um microfundamento para o multiplicador keynesiano, na qual são utilizadas concepções da abordagem da complexidade, considerarão recompensadora - e sugestiva de várias modificações e extensões uma leitura de Howitt (2006).

Economia e Sociedade, Campinas, v. 17, n. 3 (34), p. 359-381, dez. 2008. 
TG é um desdobramento da visão de Keynes do sistema econômico como um organismo complexo. Para tanto, esta seção fará uso intenso das contribuições de G. Shackle, um importante autor que, a nosso juízo, fez uma interpretação da economia de Keynes em linha e consonância com a perspectiva da complexidade aqui adotada, embora sem destacar esse vínculo - e, em certa medida e extensão, em "antecipação" a alguns desenvolvimentos em nível de substância e linguagem dos sistemas complexos que estavam por ser mais bem desenvolvidos.

\subsection{Algumas evidências na TG}

De acordo com Keynes (1936, cap. 5), entre o momento em que o produtor assume os custos e o momento em que ocorre a compra da produção pelo consumidor final, normalmente decorre algum tempo. Enquanto isso, o empresário tem que fazer as melhores previsões que lhe são possíveis sobre o que os consumidores estarão dispostos a lhe pagar. E, diz Keynes, não lhe resta alternativa senão tomar tais previsões como guia. Assim, o volume de emprego em um momento qualquer depende, em certo sentido, não apenas do estado atual das expectativas, mas também de todos os estados de expectativas que existiram no decorrer dos períodos anteriores.

Por outro lado, Keynes (1936, cap. 12) argumenta que um fato de importância fundamental é a extrema precariedade da base de conhecimento a partir da qual são realizadas as estimativas sobre o rendimento esperado. Os homens de negócio estão envolvidos em um jogo que é uma mescla de habilidade e de sorte, e cujos resultados médios são desconhecidos pelos participantes (1936, p. 110). Para a efetivação de uma determinada ação, recorre-se a uma convenção, por exemplo, a de supor que a situação vigente continuará por um tempo indefinido, a não ser que existam razões concretas para se esperar uma mudança. Esse método convencional de cálculo, por sua vez, gerará uma certa continuidade e estabilidade nos negócios se e enquanto os tomadores de decisão puderem confiar na manutenção da convenção (Keynes, 1936, p. 112).

Keynes argumenta, em uma interessante passagem da TG, que o investimento poderia ser comparado a certas competições promovidas por jornais em sua época, conhecidos como "concurso de beleza". Neles, os competidores escolheriam, dentre um conjunto de retratos femininos, um certo grupo de rostos mais bonitos, sendo declarado vencedor, porém, aquele cuja escolha correspondesse mais aproximadamente à média das preferências dos demais competidores. Assim, segundo ele,

[c]ada concorrente deverá escolher não os rostos que ele próprio considere mais bonitos, mas os que lhe parecem mais próprios a reunir as preferências dos outros concorrentes, os quais encaram o problema do mesmo ponto de vista. Não se trata de escolher os rostos que, no entender de cada um, são realmente os mais lindos, 
Fernanda Graziela Cardoso / Gilberto Tadeu Lima

nem mesmo aqueles que a opinião geral considere como tais. Alcançamos o terceiro grau, no qual empregamos a nossa inteligência em antecipar o que a opinião geral espera que seja a opinião geral (1936, p. 114).

Partindo de uma visão do sistema econômico como um organismo complexo, tal como a de Keynes, o tempo é irreversível, como se fosse uma "seta" que parte de um ponto para o qual não se pode mais voltar - o passado - e se dirige para o desconhecido - o futuro. Segundo Lima (1992), os modelos de equilíbrio geral neoclássicos sofrem de uma limitação crucial: sua incapacidade para lidar com fenômenos econômicos que se desenrolam ao longo do tempo histórico. Keynes, ao contrário, encarava a economia capitalista dentro de um contexto de tempo real. E, uma vez que o tempo histórico é uma variável assimétrica, os variados processos de tomada de decisão são permanentes e decisivamente condicionados pelas expectativas dos agentes econômicos em relação ao futuro. Mas, inferir que o período corrente é um produto da história não implica que os agentes econômicos não possam promover ajustes em suas estratégias. Pelo contrário, ao reajustarem as estratégias de ação, os agentes também alteram o contexto e as condições em que atuam. Ou, colocando em termos da abordagem da complexidade, os agentes se adaptam ao mundo - o padrão agregado - por eles co-criado, conforme elaborado por Arthur (1999, p. 1), já referido na seção 1 .

A partir de uma comparação entre a pseudo-analogia da queda das maçãs com o comportamento humano e o "concurso de beleza", pode-se inferir que ambos deixam claro que existe uma dependência em relação à vontade dos agentes e que eles elaboram estratégias. Portanto, o sistema complexo não é - e não pode ser - intermediado por relações mecânicas. Então, a associação da economia com as ciências naturais é falsa. Como a dependência em relação às vontades dos elementos constituintes do sistema se relaciona com o fato de que os resultados agregados são conseqüências não intencionais da ação dos indivíduos?

Haveria, por conseguinte, um paradoxo, pois a intenção poderia vir a diferir do resultado. Mas esse paradoxo seria apenas aparente: um sistema composto por agentes que agem em interesse próprio produzirá - ou não - no agregado resultados não intencionais. A partir da perspectiva de uma abordagem como a da complexidade, não se segue do exercício individual a geração de resultados intencionais ou individualmente redutíveis. O paradoxo real provém da interação complexa entre os átomos constituintes do sistema: o padrão interativo é complexo inclusive porque os elementos constitutivos são complexos. Tal constatação nos remete novamente a Moore e, por conseguinte, à concepção de Keynes de que a complexidade do sistema econômico é proveniente também da sua idéia de complexidade humana. A razão humana é complexa, o que implica padrões de comportamento complexos. As ações individuais, motivadas de acordo 
com o interesse individual, geram uma conseqüência agregada não intencional. Mas, apesar disso, o próprio Keynes sugeriria, a partir da sua crença racional na razão, que a ação promovida por uma razão iluminada poderia vir a resultar em conseqüências intencionadas.

Então, o problema não reside na vontade individual. É possível dotar um determinado agente - ou grupo de agentes - de política econômica da razão necessária para obter o fim último - a conseqüência intencionada. Mas, quais seriam os detalhes desse arranjo institucional que garantiria a obtenção de resultados intencionados através da política econômica? Keynes parecia acreditar que estava desenvolvendo uma teoria que consubstanciaria essa razão iluminista necessária para gerar resultados determinados em nível de política econômica. $\mathrm{Ou}$ seja, embora o sistema seja complexo, seria possível exercer a razão de maneira que os resultados agregados fossem mais desejáveis ou próximos aos intencionados.

\subsection{A caleidoscopia keynesiana}

Antes que Keynes pudesse explicar a fonte e a natureza do desemprego involuntário, ele se viu forçado a mostrar que essa noção é logicamente existente, ou seja, que ela não contém uma autocontradição interna. Assim, Keynes abandona a visão clássica e parte de uma perspectiva inovadora: se e em que sentido a demanda efetiva por bens em geral é necessariamente igual à sua oferta. Nas palavras do próprio Keynes (1936),

[s]e a teoria clássica é apenas aplicável ao caso do pleno emprego, torna-se obviamente enganoso aplicá-la aos problemas do desemprego involuntário... Os teóricos da escola clássica são comparáveis a geometras euclideanos em um mundo não euclideano, os quais, descobrindo que, na realidade, as linhas aparentemente paralelas se encontram com muita freqüência, as criticam por não se conservarem retas, como único recurso contra as desastrosas interseções que se produzem. Sendo esta a realidade, não há, de fato, nenhuma outra solução a não ser rejeitar o axioma das paralelas e elaborar uma geometria não euclideana. A ciência econômica reclama hoje uma medida desse gênero (p. 24).

Segundo Shackle (1974), central a essa idéia é o fato de que as concepções de diferentes pessoas em relação ao que ocorrerá a partir de suas ações planejadas podem ser infinitamente variadas e até incompatíveis. O que é o equilíbrio geral senão o resultado de uma pré-conciliação cuidadosamente organizada de escolhas racionais? O que Keynes queria dizer, então, a partir de sua perspectiva da complexidade, é que o mundo descrito pelos clássicos é uma concepção artificial, remota e abstrata.

Keynes, argumenta Shackle, lida com a incerteza, com a pluralidade de respostas que um agente pode dar a qualquer questão quando a evidência não é 
única, completa ou conclusiva. De acordo com o autor, no TP, Keynes realiza um estudo genial de como, apesar de uma insuficiência de conhecimento, um guia racional e logicamente defensável pode ser obtido. No artigo de 1937, o qual Keynes escreveu em resposta a críticos da TG, o autor explicita como os homens deliberadamente e conscientemente, mesmo sob incerteza, tornam possível a tomada de decisões baseando-se nas convenções.

Shackle destaca que, no TP, o propósito central de Keynes é responder à seguinte questão: qual é a natureza da ligação entre um dado corpo de evidências e alguma proposição para a qual essas evidências são dadas como relevantes? Ou, em outras palavras, quais circunstâncias comandam o grau de sustentação - ou o grau de crença racional, de acordo com Keynes - que a evidência apropriadamente concede à proposição? O autor então sugere que há uma associação positiva entre o que Keynes chama de peso do argumento no TP e o grau de crença racional.

De acordo com Shackle, a incerteza significa duas coisas: a base fragmentária, ilusória e vaga, e o escopo que isso concede para mudanças de interpretação abruptas e inexplicáveis. A incerteza, diz o autor, é, então, o fator caleidoscópico. Quanto menor a força e o poder de convicção que a evidência mostra em favor de uma resposta particular ou uma hipótese, maior será a facilidade de se desviar a atenção para outra hipótese. Nas palavras do autor, "[u]ncertainty then, we seem bound to conclude, is a unity, though with many faces" (1974, p. 43). Mas vale ressaltar aqui, novamente, que a incerteza inerente ao sistema econômico é resultante da complexidade dos elementos constituintes desse sistema. Ou seja, a visão do sistema econômico como um todo orgânico complexo de Keynes decorre, inclusive, de sua visão da natureza humana como complexa.

A fim de explicitar e diferenciar a maneira particular de Keynes de formular teorias, Shackle se refere a ela como caleidoscópica. O próprio Keynes se utilizou dessa terminologia no Tratado da Moeda (TM). Nas palavras do próprio Keynes, "[t]he effect of moving a kaleidoscope on the coloured pieces of glass within is almost a better metaphor for the influence of monetary changes on price levels" (CW, V, p. 81). Shackle relaciona a noção de teoria caleidoscópica com a visão de que as expectativas são a todo instante tão pouco fundamentadas em dados e tão sujeitas a mudanças que, a qualquer momento, assim como as partículas de um caleidoscópio, qualquer "movimento" dissolve os padrões anteriormente estabelecidos. Ou, colocando na linguagem contemporânea da teoria da complexidade, trata-se de um processo altamente sensível às condições iniciais.

Nesse contexto, Shackle sugere que a única interpretação que permite a reconciliação entre esse contexto e a idéia de equilíbrio é ele ser entendido como o ajustamento efêmero que, de tempos em tempos, ocorre quando, por acidente ou 
coincidência, os acontecimentos se assemelham ao equilíbrio normal marshalliano. $\mathrm{O}$ autor se refere a essas pausas no decorrer da história como caleidoscópicas. Nas palavras do autor,

[i]t may be fair to say that Keynes in all this field has matched the elusiveness, the unseizableness of the ideas and problems by a masterly resort to elliptical language. When mankind cannot penetrate and dissect something, it copes with that difficulty as the oyster does with the instrumensive particle of grit, by encapsulating it in a gleaming envelope, of pearl or of grammatical forms (Shackle, 1974, p. 47).

Shackle indica que Keynes estava engajado numa análise de equilíbrio parcial. Keynes se refere a investimento como um dado tipo de capital e, certamente, somente quando o aumento do investimento é feito por uma indústria isolada, uma pequena parte de todo o sistema, a renda esperada será uma função decrescente da taxa corrente de investimento. Em relação ao efeito de um aumento geral do investimento em todas as indústrias, com seu efeito multiplicador sobre o tamanho da produção em geral, Shackle sugere que Keynes pouco se referiu a essa questão. A explicação para tal residiria no fato de que o que Keynes pretendia com a TG era que ela fosse uma coleção de instrumentos, mas não constituindo um modelo rígido da sociedade econômica. Nas palavras do autor,

Keynes believed in the eclectic use of general ideas, such ideas as the essentially speculative character of the interest rate, the mutable and precarious basis of the inducement to invest the consequences of the existence of liquid, non-specific asset, in order to analyse and prescribe for each and any situation as an individual problem in its own right, not as a mere illustration of some preordained mode of history (Shackle, 1974, p. 49, ênfase original).

Shackle argumenta que o teórico econômico se depara com problemas de método insolúveis. Como poderia ser de outra forma, questiona o autor, quando o objeto de estudo se refere a questões humanas? Referir-se à economia como lógica pura da escolha é algo então duvidoso: se a ação é o resultado da aplicação pura da razão a circunstâncias adequadamente conhecidas, pode ser definida como uma escolha? Além disso, há ainda a moeda, a qual não teria lugar num sistema puramente racional, por conta de seus dois propósitos, diligência e liquidez, pois a racionalidade supõe conhecimento completo, o qual aboliria esses dois propósitos. Em verdade, acrescentaríamos nós, há ainda a moeda na qualidade, ela própria, de signo complexo. Em face de tais dilemas, questiona o autor, como o economista pode esperar encontrar um modelo geral e exato?

A economia é essencialmente um assunto impreciso, destaca Shackle, pois ela trata de coleções de vastos números de coisas dissimilares. Nas palavras do autor, "[e]conomics is the art and science of imprecision. It operates with capsules or 'black boxes', into whose contents we do not enquire. Or it treats of the central enigmas of our experience in terms of words so familiar that they banish misgivings and inhibit curiosity" (1974, p. 74, ênfase original). 
Fernanda Graziela Cardoso / Gilberto Tadeu Lima

\section{Considerações finais}

A abordagem da complexidade, recentemente aplicada à economia, tem como idéia central a de que as ações individuais promovem conseqüências não intencionais como resultado de um processo de auto-organização, permitindo o funcionamento do sistema. Ou seja, o todo, enquanto propriedade emergente, não é dedutível imediata e diretamente a partir de um "componente representativo". $\mathrm{Na}$ verdade, posto que essa abordagem representa um esforço intelectual ambicioso de compreensão do funcionamento de sistemas altamente organizados, mas descentralizados e compostos de um número muito grande de componentes individuais, heterogêneos, a própria noção de "componente representativo" é insuficientemente representativa.

Conforme argumentado acima, o próprio Keynes explora essa idéia de consequiências não intencionais, o que é patente, por exemplo, na sua elaboração de paradoxo da poupança. Assim, interpretando a abordagem da complexidade a partir da filosofia mooreana, no final o que importa não é apontar quais são as conseqüências infinitas de determinada ação, mas definir o resultado que se obtém a partir da interação delas.

Porém, o aspecto geral da TG, dentre outras acepções mais diretamente inferíveis, implica que tal teoria pretende definir uma lei geral da determinação do produto e do emprego. Ou seja, se pretende uma lei geral invariável no tempo e no espaço. Mas não seria algo contraditório quando se analisa de uma perspectiva da abordagem da complexidade? Dito de outro modo, partindo da idéia de nãolinearidade e de conseqüências não intencionais que se auto-organizam como uma propriedade emergente de um sistema complexo, quão contraditória é a busca por uma teoria geral? Por outro lado, o princípio da demanda efetiva de Keynes, interpretado neste artigo como mecanismo essencial de adaptação do produto em uma economia de mercado, é suficientemente aberto para não determinar um préresultado, o que, de certa forma, acabaria com o aspecto contraditório de uma teoria que se pretende geral, mas que está em consonância com a abordagem da complexidade. Mas, conforme notado pelo próprio Keynes, não importa a caleidoscopia que envolve as ações individuais, pois no agregado finda emergindo uma relativa estabilidade. Sem embargo, tal constatação nos remete a outra questão: o que há de característico nos processos ditos complexos que faz com que se manifeste no agregado uma dinâmica de relativa estabilidade? Daí, portanto, a fecundidade de uma interação entre a abordagem da complexidade e a economia do emprego de Keynes.

\section{Referências bibliográficas}

ALBIN, P. S. Barriers and bounds to rationality. D. K. Foley (Ed.). Princeton: Princeton University Press, 1998. 
ANDRADE, R. P. A agenda do keynesianismo filosófico: origens e perspectivas. Revista de Economia Política, v. 20, n. 2, abr./jun. 2000.

ARTHUR, W. B. Complexity and the economy. Science, p. 107-109, Apr. 1999.

; DURLAUF, S.; LANE, D. Introduction. In:

(Ed.). The economy as an evolving complex system II. Reading, MA: Addison-Wesley, 1997.

CARABELLI, A. On Keynes's method. London: Macmillan Press, 1988.

COATES, J. The claims of common sense: Moore, Wittgenstein and the social sciences. Cambridge: Cambridge University Press, 1996.

DAVIS, J. B. Keynes's philosophical development. Cambridge: Cambridge University Press, 1994.

DEQUECH, D. Fundamental uncertainty and ambiguity. Eastern Economic Journal, v. 26, n. $1,2000$.

FOLEY, D. Unholy Trinity: labor, capital, and land in the new economy. London: Routledge, 2003.

GRIBBIN, J. Deep simplicity: bringing order to chaos and complexity. London: Random House, 2005.

HOLLAND, J. Hidden order: how adaptation builds complexity. New York: Basic Books, 1995.

. The end of science: facing the limits of knowledge in the twilight of the scientific age. New York: Broadway Books, 1997.

HOWITT, P. The microfoundations of the Keynesian multiplier process. Journal of Economic Interaction and Coordination, v. 1, n. 1, May 2006.

KEYNES, J. M. (1921). Treatise on probability. The Collected Writings of John Maynard Keynes. Ed. by D. Moggridge, v. VIII. London: Macmillan, 1972.

(1926). Francis Ysidro Edgeworth. The Collected Writings of John Maynard Keynes. Ed. by D. Moggridge, v. X. London: Macmillan, 1972.

(1931). A treatise on money. The Collected Writings of John Maynard Keynes. Ed. by D. Moggridge, v. V e VI. London: Macmillan, 1972.

(1933). Alfred Marshall. The Collected Writings of John Maynard Keynes. Ed. by D. Moggridge, v. X. London: Macmillan, 1972.

(1936). A teoria geral do emprego, do juro e da moeda. São Paulo: Editora Nova Cultural, 1985. (Coleção Os Economistas).

(1937). A teoria geral do emprego. In: SZMRECSÁNYI, Tamás (Org.). John Maynard Keynes. Editora Ática, 1984.

(1938). My early beliefs. The Collected Writings of John Maynard Keynes. Ed. by D. Moggridge, v. X. London: Macmillan, 1972. 
Fernanda Graziela Cardoso / Gilberto Tadeu Lima

KEYNES, J. M. The general theory and after: defense and development. The Collected Writings of John Maynard Keynes. Ed. by D. Moggridge, v. XIV. London: Macmillan, 1973.

KOPPL, R. Animal spirits. Journal of Economic Perspectives, v. 5, n. 3, p. 203-210, 1991.

LEWIN, R. Complexity: life at the edge of chaos. Chicago: The University of Chicago Press, 1992.

LIMA, G. T. Em busca do tempo perdido: a recuperação pós-keynesiana da economia do emprego de Keynes. Rio de Janeiro: BNDES, 1992.

MINI, P. Keynes, Bloomsbury and the general theory. Basingstoke: Macmillan, 1991.

MOORE, G. E. Principia ethica. Cambridge: Cambridge University Press, 1903.

NICOLIS, G.; PRIGOGINE, I. Exploring complexity: an introduction. New York: W. H. Freeman \& Company, 1989.

O’DONNELL R. M. Keynes: philosophy, economics \& politics. London: Macmillam, 1989.

PRIGOGINE, I.; STENGERS, I. Order out of chaos: man's new dialogue with nature. New York: Bantam Books, 1984.

PRYOR, Frederic L. Economic evolution and structure: the impact of complexity on the U.S. economic system. New York: Cambridge University Press, 1995.

ROSSER JR., J. B. On the complexities of complex economic dynamics. Journal of Economic Perspectives, v. 13, n. 4, 1999.

SHACKLE, G. L. S. Keynesian kaleidics: the evolution of a general political economy. Chicago: Edinburgh University Press, 1974.

WALDROP. Complexity: the emerging science at the edge of order and chaos. New York: Touchstone, 1992. 